\title{
Advanced Materials Congress Celebrating 10th Years of Establishment
}

\author{
Ashutosh Tiwari* iD \\ Secretary General, International Association of Advanced Materials, Gammalkilsvägen 18, Ulrika 590 53, Sweden \\ *Corresponding author: E-mail: secretarygeneral@iaamonline.org; Tel: (+46) 1313-2424
}

DOI: $10.5185 /$ amlett.2020.021468

In the past ten years, Advanced Materials Congress, AMC, has gone through a glorious journey. The congress has achieved a lot in a decade, and, in the upcoming decades, the AMC is all set to launch new assemblies to move further ahead in its pursuit of expanding the scope of Advanced Materials. In the AMC assemblies, the International Association of Advanced Materials, IAAM, offers education and research forums for advancing materials to global excellence. By February 2020, IAAM has successfully organized 32 assemblies of AMC in the four major continents: Europe, Asia, Australia, and America. In these ten years, the Advanced Materials Congress, AMC, has facilitated one of the largest global platforms for advanced materials researchers to discuss the trends of this field. In the new decade, it is the sincerest hope of IAAM to establish inland assemblies and forums for enriching the contemporary disciplines for the larger benefits of the society. The attempts of IAAM take a lead further to stimulate the advancement of materials towards sustainable and green world by 2030.

Advanced Materials Congress, AMC, regularly organized by a non-profit organization, International Association of Advanced Materials, IAAM since 2011, is a well-known international assembly that focuses on advanced materials science, engineering, and technology (Fig. 1) [1-4]. AMC offers truly comprehensive platforms for students, researchers, policy makers, entrepreneurs and professionals from academia and industry to promote multi-inter-transdisciplinary research, innovation, and technology in the field of advanced materials $[\mathbf{5 , 6}]$.

\section{JOURNEY OF WORLD}

\section{Advanced Materials Congress}

Connecting Materials Science, Engineering \& Technology

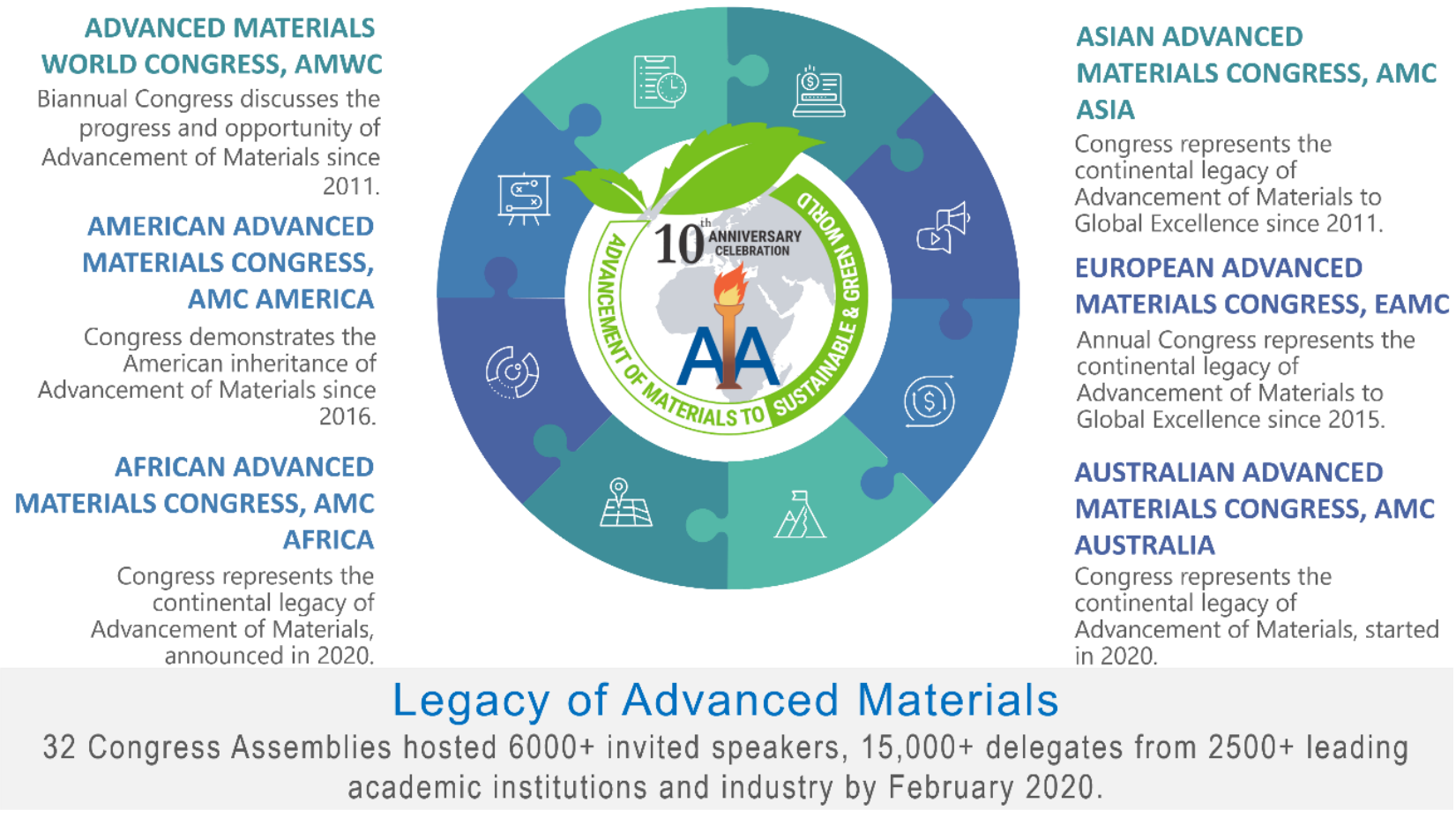

Fig. 1. In ten years of establishment, Advanced Materials Congress, AMC have actively created a global forum straddling across the Europe, Asia, Australia, Africa and America to achieve together the agenda of next decade, 2030, 'The Advancement of Materials for a Sustainable and Greener World'. 


\section{Advanced Materials Letters www. vbripress.com/aml}

Since commencement of AMC, IAAM has hosted over 15,000 representatives from over 100 countries in its past assemblies held in the famous world-wide destinations such as city of Nobel, Stockholm (Sweden); Singapore (Lion City, science and technology hub in Asia), Miami, Orlando (USA); Sydney (Australia); Jinan (Spring City, co-hosted by Jinan University, China), Delhi (co-hosted by University of Delhi, India), Izmir (co-hosted by İzmir Institute of Technology, Tukey) and many more (Fig. 2 \& 3) [7-13]. Initially, AMC was conducted on land in alliance with renowned universities up to 2013. IAAM noticed the possibility of organizing a unique venue such as congress centre at a cruise ship, which could bring high-yield collaboration opportunities for delegates. Encompass with the highest optimality of Congress, IAAM has grown with a prodigious format of 'Knowledge Experience at Sea' so that delegates could ensure maximum interactions and the most vibrant discussions in a congenial environment altogether for advancing materials for translational venues [14].

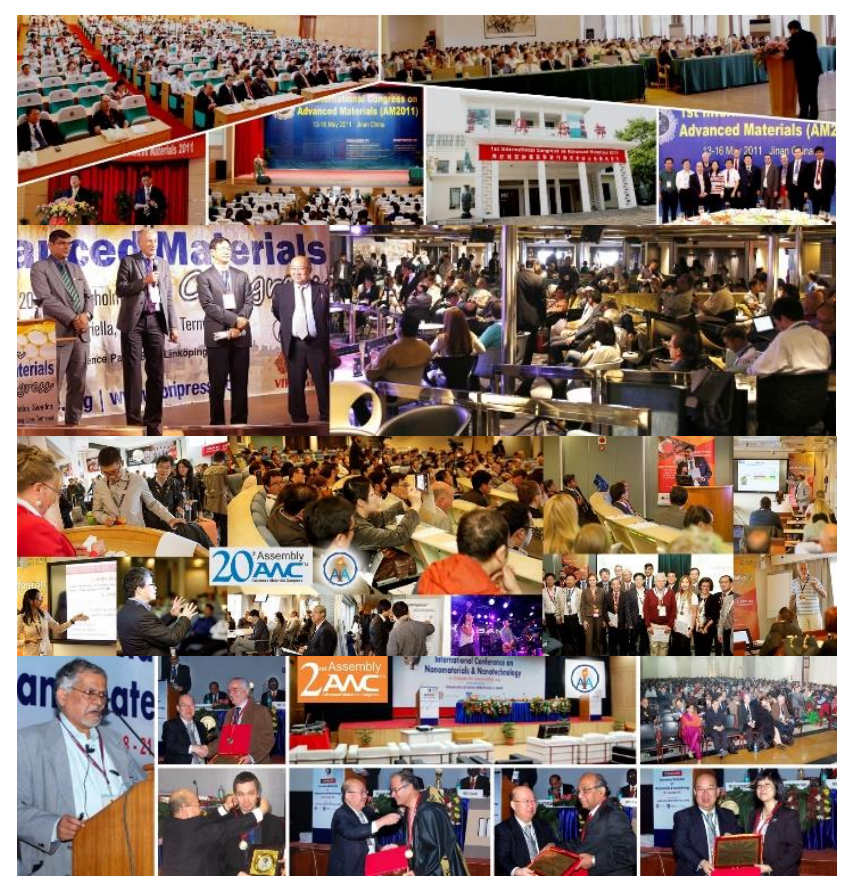

Fig. 2. Advanced Materials Congress, AMC has successfully conducted 32 assemblies until February 2020 to promote advanced materials in both academia and industry.

The $21^{\text {st }}$ century has brought a technological revolution with itself, and with this revolution, it had become imperative - as a scientific community - to realize that technology can prove to be extremely helpful to empower society. With time, it was also clear that collaborations are the way to move forward to achieve wholesome technological advancement. As IAAM started with its pursuit of facilitating research networks, it became obvious that advanced materials formed a promising sector that could help solve a wide range of societal issues. The right way forward was to create an extensive network and include the scientific elites as well as the young and upcoming researchers in order to develop the sector of advanced materials quickly [15-18]. From the very initial of phases, prominent scientists with affiliations from highly regarded institutes all over the world joined the International Association of Advanced Materials, IAAM and in no time, the organization made its mark in the world of advanced materials. Ever since then, the organization has been organizing and facilitating highly interactive forums for the researchers, professionals, and organizations of the advanced materials sectors.

\section{Advanced Materials Congress}

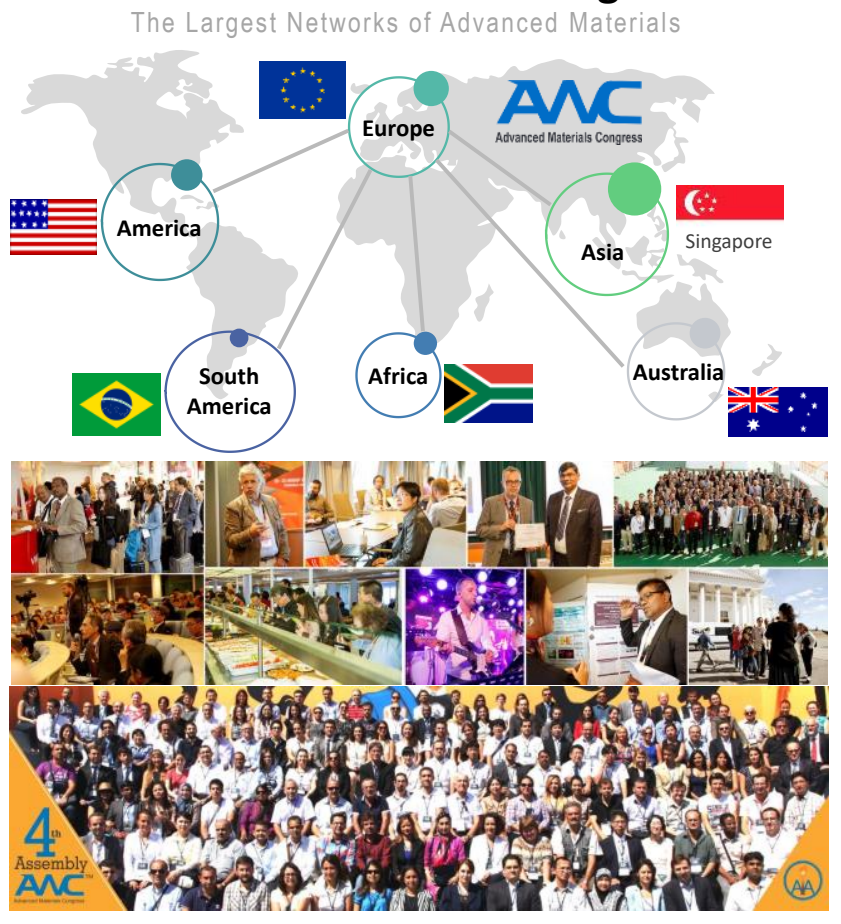

Fig. 3. The AMC assemblies expedite contemporary research fields of Advanced Materials Science, Engineering, and Technology by creating world largest networks of multi-inter-trans-disciplinary research, innovation, and technology.

The multidisciplinary conferences that the association organizes are conducted in such a way that they create a perfect amalgamation of various research areas and provide a valuable experience to the delegates. The association has made constant efforts to induce collaborations and build partnerships among professionals and researchers working in different branches of science, engineering and technology. Throughout the past decade, the International Association of Advanced Materials, IAAM, has utilized widely regarded international congresses to facilitate discussions on critical fields like nanomaterials, energy materials, composite materials, metamaterials, functional materials, healthcare materials, applied materials, etc. [19-22] Another major contribution that the International Association of Advanced Materials, IAAM has made in last ten years is that it has put significant efforts to facilitate the commercialization of valuable research into tangible products for the end-user. 


\section{Advanced Materials Letters www. vbripress.com/aml}

With the arrival of the year 2020, the International Association of Advanced Materials, IAAM, completes ten years of what has been an absolutely wondrous and glorious journey. On its way, the association has deeply infused the spirit of partnership, collaboration, and team building in the world of advanced materials. In the process, IAAM has achieved great heights and is widely regarded as a prestigious organization today. As we take a look back at these ten years, it can be found that IAAM made boundless contributions to the advanced materials world while working with the motto of "Advancement of Materials to Global Excellence" $[\mathbf{3}, \mathbf{4}]$.

During these ten years, IAAM also regularly organized about 20 consortiums as part of its congress assemblies. These consortiums proved to be a valuable bridge between the academic, researchers, scientists, and the industry professionals [3]. By facilitating forums for knowledge sharing, building joint infrastructures, and to bring various business giants together, the International Association of Advanced Materials, IAAM, has significantly enhanced the quality and efficiency of the partnerships that are formed within the scientific world and also between the industry professionals and scientific elites (Fig. 4). The idea of working with young and innovative minds has proved to be extremely successful and paved the way for some cuttingedge, modern, and highly useful technology for the market. Looking at the developments that IAAM has accelerated in ten years, it is quite reasonable to say that the International Association of Advanced Materials, IAAM has grown by leaps and bounds.

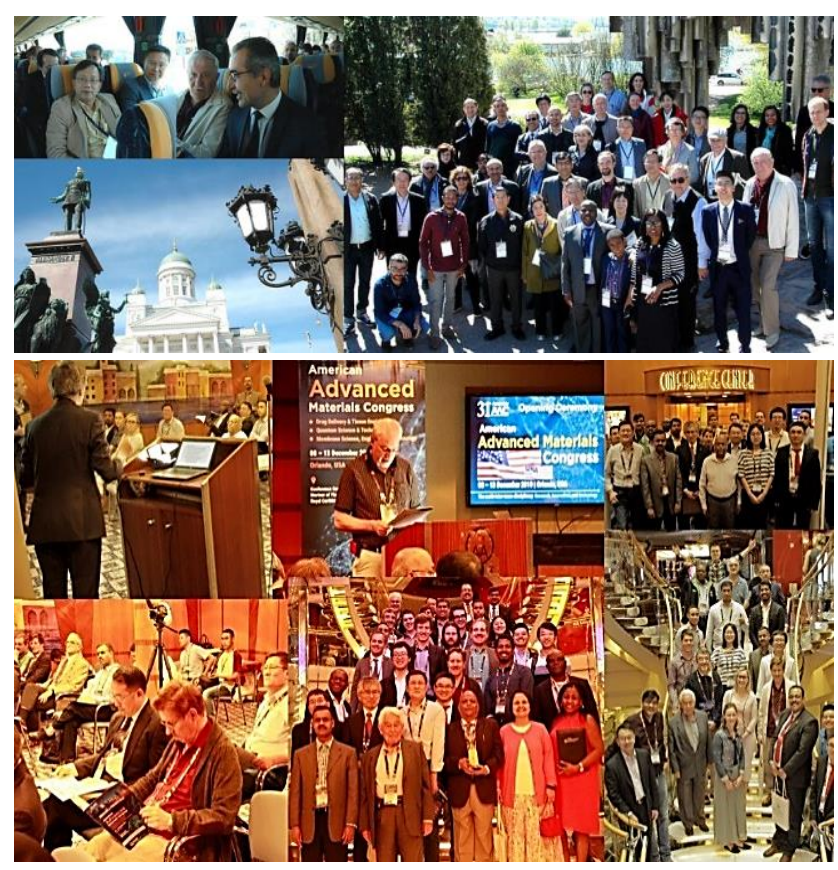

Fig. 4. With the stupendous format of 'Knowledge Experience at Sea', in 2020, the Advanced Materials Congress, AMC is going to serve as a platform for a wide variety of purposes such as a mean of creative expression for interpersonal advancements and the pursuit of excellence. These assemblies also help to build mutual identity and celebrate multicultural traditions.
Along with several other forums, the Advanced Materials Congress, AMC has also had a very fruitful and remarkable journey. The first assembly of this congress was organized in China and today, it has grown to become one of the largest global networks of advanced materials researchers and entrepreneurs. In the future, the association hopes to perpetuate an enthusiasm in the researchers to achieve a sustainable and green world and also achieve greater heights and levels of cooperation (Fig. 5).

In the year 2020, AMC assemblies will be geared up to conduct amelioration of challenges of society in general. The assemblies will be taking place to the far-flung corners of the world as the announced assemblies of AMC:

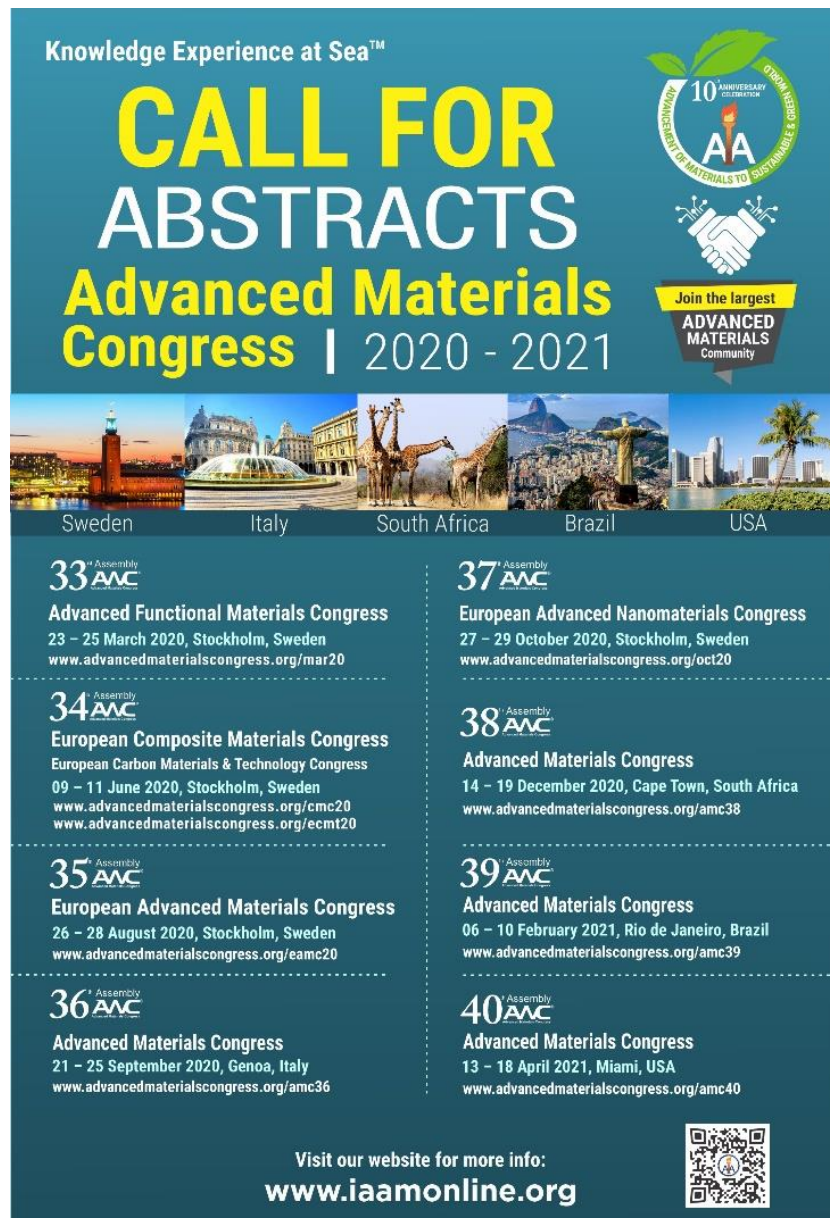

Fig. 5. Upcoming assemblies of Advanced Materials Congress, AMC as step towards the "Advancement of materials to sustainable and green world".

The AMC assemblies create worldwide consortiums of translational research and innovation in order to bridge the gap between academia and industry. With the ease of this platform, the delegates get the opportunity to share their research work as well as build a network of talented resources with an abundance of knowledge. Moreover, this innovative approach of 'Knowledge Experience at Sea' provides a distinctive opportunity for the Advanced Materials community to have manifold discussions in a panoptic fashion. It enables a highly extensive coordination 


\section{Advanced Materials Letters www. vbripress.com/aml}

of various substantial research fields of Advanced Materials, Science and Technology as well.

One of the greatest concerns of the International Association of Advanced Materials, IAAM is to ensure the 'Advancement of Materials to Global Excellence' [22]. For this reason, IAAM has set its specific benchmarks in line in terms of quality. Since 2010 IAAM has refined its way to make more and wider access of AMC assemblies for every individual. And in this decade, the Association hopes to continue with the same momentum for the betterment of society; for the betterment of science and technology; and for the betterment of advancement materials community.

\section{Keywords}

Advanced Materials Congress, AMC assembly, International Association of Advanced Materials, IAAM.

\section{Acknowledgement}

The author sincerely acknowledges the contributions of the International Association of Advanced Materials, IAAM members and delegates for their selfless efforts towards endorsement of the advanced materials for global excellence.

\section{References}

1. International Association of Advanced Materials, viewed 23 January 2020, <https://www.iaamonline.org/>.

2. Advanced Materials Congress, viewed 23 January 2020, $<$ https://www.iaamonline.org/advanced-materials $>$.

3. Tiwari, A.; Adv. Mater. Lett., 2020, 11, 20011455 (1-6).

4. "The Journey of a Decade to Advancing Materials", blog post 10 January 2020, viewed 23 January $\mathbf{2 0 2 0}$,

<https://www.iaamonline.org/blog/the-journey-of-a-decade-toadvancing-materials/>.

5. "The Story of IAAM - A Journey to Achieving Global Excellence", blog post 18 August 2019, viewed 23 January 2020,

$<$ https://www.iaamonline.org/blog/the-story-of-iaam-a-journey-toachieving-global-excellence/>

6. Spindle, B., "Indian researcher creates global knowledge center for advanced materials in Stockholm", Nordiska Projekt, 18 December 2018, viewed 23 January 2020,

$<$ https://www.nordiskaprojekt.se/2018/12/18/indisk-forskareskapar-globalt-kunskapscentrum-for-avancerade-material-istockholm/>.

7. "Proceedings of American Advanced Materials Congress 2019, Orlando", blog post 31 December 2019, viewed 23 January 2020, $<$ https://www.iaamonline.org/blog/proceedings-of-americanadvanced- materials-congress-2019-orlando/>.

8. "Report of the Asian Advanced Materials Congress - 2019, Singapore", blog post 21 November 2019, viewed 23 January 2020 , $<$ https://www.iaamonline.org/blog/asian-advanced-materialscongress-2019/>.

9. "Report of the October edition of the Advanced Materials Congress 2019”, blog post 24 October 2019, viewed 23 January 2020, $<$ https://www.iaamonline.org/blog/report-of-the-october-edition-ofthe-advanced-materials-congress-2019/>.

10. "Report of the 27th assembly of Advanced Materials Congress", blog post 30 August 2019, viewed 23 January 2020,

<https://www.iaamonline.org/blog/report-of-the-27th-assembly-ofadvanced-materials-congress/>.

11. "Built Multi-Inter-Trans-Disciplinary Future of Functional Materials!", blog post 20 May 2019, viewed 23 January 2020, $<$ https://www.iaamonline.org/blog/built-multi-inter-transdisciplinary-future-of-functional-materials/>.

12. "700 researchers from 75 countries gather in Stockholm", Meetings International, 25 January 2019, viewed 23 January 2020, <https://www.meetingsinternational.se/news.php?id=4046>

13. "Advancement of Materials to Global Excellence in 2018", blog post 20 December 2018, viewed 23 January 2020, $<$ https://www.iaamonline.org/blog/advancement-of-materials-toglobal-excellence-in-2018/>.

14. Gale, C.; "Advanced Materials Congress Takes a 'Knowledge Experience' Cruise", PCMA Convene, 29 March 2019, viewed 23 January 2020, <https://www.pcma.org/25th-advanced-materialscongress-meetings-we-like/>.

15. "Promo video of the European Advanced Materials Congress (EAMC) 2020, Stockholm, Sweden", online video, viewed 23 January 2020. 〈https://www.youtube.com/watch?v=Q7fvBju-9hk>

16. "23rd Assembly of Advanced Materials Congress, November 2018", online video, viewed 23 January 2020. <https://www.youtube.com/watch?v=WPzLLHv0mnM>.

17. "Prof. Norman Munroe | Knowledge Experience at Sea | IAAM", online video, viewed 23 January 2020 . https://www.youtube.com/watch?v=xFclrVAxqfI\&list=>.

18. Dr. Dmitriy Berillo |Knowledge Experience at Sea | IAAM, online video, viewed 23 January $\mathbf{2 0 2 0}$,

<https://www.youtube.com/watch?v=Ag3JVtCdheE\&list=>.

19. "Prof. Enge Wang; Advanced Materials Laureate 2018", online video, viewed 23 January 2020,

<https://www.youtube.com/watch?v=DftRmSz-o_M\&t=67s>

20. “Prof. Herbert Gleiter | Advanced Materials Laureate 2019", online video, viewed 23 January 2020 ,

<https://www.youtube.com/watch?v=rxdYgcABolQ\&t=6s >.

21. "American Advanced Materials Award Lecture, Prof. Ramesh K Agarwal, Washington University, St. Louis", online video, viewed 23 January 2020

<https://www.youtube.com/watch?v=NtxpvDmFW3w>

22. "Be a Part of World's Largest Global Network of Advanced Materials Researchers: Become IAAM Member" blog post 29 November 2019, viewed 23 January 2020,

$<$ https://www.iaamonline.org/blog/be-a-part-of-worlds-largestglobal-network-of-advanced-materials-researchers-become-iaammember/>. 